\title{
A PERCEPÇÃo DO AGENTE COMUNITÁRIO DE SAÚDE PARA IDENTIFICAR A DEPRESSÃo*
}

\section{Olívia Lina Harada ${ }^{1}$; Marcos Hirata Soares ${ }^{2}$}

Objetivou-se, aqui, avaliar a percepção sobre o preparo do agente comunitário de saúde (ACS) para detecção da depressão, pois esse profissional representa importante papel na identificação desse transtorno. Os nove ACSs responderam questionário com perguntas abertas e autoaplicáveis. A análise dos resultados permitiu a elaboração de três temas para a discussão: atitudes e conhecimentos sobre transtornos mentais e depressão, capacitação em saúde mental, assistência em saúde mental e apoio matricial. Concluiu-se que o conhecimento do ACS baseia-se no consenso coletivo e que, muitas vezes, se torna precário frente à demanda, suscitando, assim, a busca por melhor capacitação desses profissionais.

Descritores: Depressão; Saúde Mental; Atenção Primária à Saúde.

\section{The Perception of the Community Health Agent to Identify Depression}

Considering that community health agents (CHA) play an important role in detecting depression, the objective of the present study was to evaluate their perception in identifying this disorder. The nine CHA answered a questionnaire with open, self-administered questions. Results analysis resulted in three discussion themes: attitudes and knowledge about mental disorders and depression, preparation in mental health, mental health care and headquarter support. It was concluded that the CHA knowledge is based on collective consensus and that it often becomes deficient in view of the demand, thus calling for a better preparation of those professionals.

Descriptors: Depression; Mental Health; Primary Health Care.

\section{LA PERCEPCIÓN DEL AGENTE COMUNITARIO DE SALUD PARA IDENTIFICAR LA DEPRESIÓN}

Se objetivó evaluar la percepción sobre la preparación del agente comunitario de salud (ACS) para la detección de depresión, dado que tal profesional representa un importante papel en la identificación de este transtorno. Los nueve ACS respondieron un cuestionario con preguntas abiertas y autoaplicables. El análisis de los resultados permitió la elaboración de tres temas para su discusión: actitudes y conocimientos sobre transtornos mentales y depresión, capacitación en salud mental, atención en salud mental y el apoyo matricial. Se concluyó en que el conocimiento del ACS se basa en el consenso colectivo y que muchas veces resulta precario frente a la demanda, determinándose así la necesidad de una mejor capacitación de esos profesionales.

Descriptores: Depressión, Salud Mental, Atención Primaria de Salud.

\footnotetext{
* Parte da monografia de conclusão do curso de Bacharelado em Enfermagem da Universidade Estadual de Londrina. Universidade Estadual de Londrina (UEL), PR, Brasil:

1-Aluna do curso de Bacharelado em Enfermagem, autora da Monografia. E-mail: linaharada@yahoo.com.br

2-Enfermeiro, Orientador da Monografia, Professor Assistente de Saúde Mental, Departamento de Enfermagem do Centro de Ciências. E-mail: mhirata@uel.br.

Endereço para Correspondência: Avenida Robert Koch, 60, Bairro Vila Operária, CEP 86038-350. Londrina, PR, Brasil. Número Artigo

\begin{tabular}{|c|c|c|c|c|c|c|}
\hline \multirow{4}{*}{ SMAD 2010} & \multirow{3}{*}{$\begin{array}{l}\text { Volume } \\
\text { Volumen }\end{array}$} & \multirow{2}{*}{\multicolumn{2}{|c|}{ Numoro }} & \multirow{2}{*}{\multicolumn{2}{|c|}{ 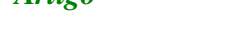 }} & \multirow{3}{*}{$\begin{array}{c}\text { SMAD, Revista Eletrônica Saúde Mental } \\
\text { Álcool e Drogas }\end{array}$} \\
\hline & & & & & & \\
\hline & & 6 & Numero & Artículo & 6 & \\
\hline & & & Number & Article & & \\
\hline
\end{tabular}
}




\section{Introdução}

A diretriz para assistência em saúde mental, atualmente, tem sido o fortalecimento da articulação entre saúde mental e a Atenção Básica de Saúde (ABS). Isso se deve em grande parte à longa história de lutas e reivindicações que resultaram na aprovação da atual Lei $n^{\circ}$ 10.216/01, ou Lei Nacional da Reforma Psiquiátrica. Nesse contexto, desenvolve-se o papel da ESF (Estratégia de Saúde da Família) na saúde mental, da qual um dos componentes dessa equipe, o agente comunitário de saúde (ACS), tem como principais atribuições coletar informações referentes às necessidades de saúde da população, identificar e encaminhar usuários com problemas à unidade de saúde $\mathrm{e}^{(1)}$.

Partindo da informação de que o ACS tem o conhecimento das necessidades da população e a função de identificar os problemas da mesma, assim como a Atenção Básica de Saúde tem como uma das diretrizes o cuidado integral, postula-se que ele constitui ferramenta essencial para detecção de patologias importantes, como a depressão, que causa ônus ao indivíduo, à sociedade, sendo também fator agravante de outras doenças. Foi objetivo deste estudo conhecer a percepção sobre seu preparo para a identificação de sinais e sintomas sugestivos de depressão e a sua visão geral sobre saúde mental.

Para a Organização Mundial da Saúde-OMS ${ }^{(2)}$, depressão é definida como transtorno mental comum, caracterizado por humor deprimido, perda de interesse ou prazer, sentimento de culpa ou baixa autoestima, distúrbio do sono ou apetite, baixa energia, e baixa concentração. Esses problemas podem se tornar crônicos, ou recorrentes, e levar a prejuízos

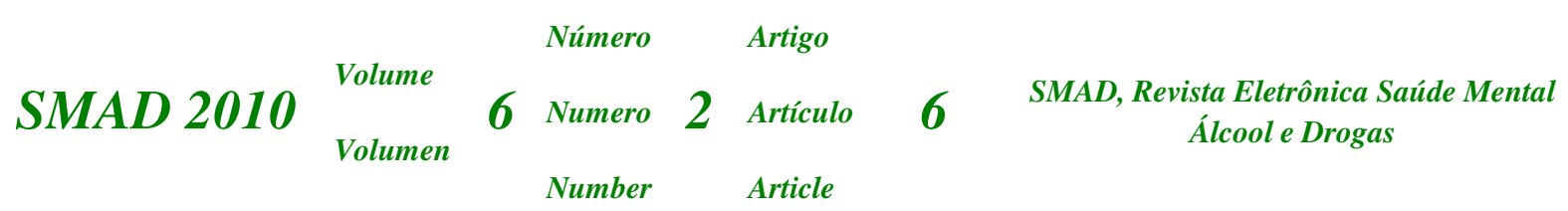


substanciais à capacidade de realizar as atividades diárias. Um estudo ${ }^{(3)}$ refere que $50 \%$ dos pacientes deprimidos não são diagnosticados em cuidados primários, da mesma forma que $30 \%$ dos pacientes internados em hospitais clínicos, $36 \%$ dos idosos e $42 \%$ dos pacientes com neoplasias.

A depressão é tida como uma das doenças mais incapacitantes, conforme pesquisas da $\mathrm{OMS}^{(4)}$. As afecções mentais e neurológicas respondem por $30,8 \%$ de todos os anos vividos com incapacidade, sendo que a depressão causa a maior proporção de incapacidade, representando quase $12 \%$ do total. Estudo realizado no Rio de Janeiro, RJ, aponta a depressão como a síndrome mais frequente entre os pacientes com transtornos mentais comuns. Também se constatou que eram, em grande parte, episódios severos e recorrentes ${ }^{(5)}$, ou seja, com grande potencial para suicídio.

Dessa forma, a prevalência da depressão e dos transtornos mentais em geral é de grande preocupação, não só pelo transtorno em si, mas também pelo risco de suicídio de pacientes com esse problema de saúde e pela relação que existe com "doenças físicas". Indivíduos com transtornos mentais podem ter o sistema imunológico prejudicado, apresentar condutas alimentares e higiênicas inadequadas e, consequentemente, adoecer, assim como portadores de doenças orgânicas crônicas são mais vulneráveis à depressão.

\section{Processo de Reforma Psiquiátrica}

No final da década de 1980, a Reforma Psiquiátrica e a Reforma Sanitária eclodiram em período no qual a população buscava a consolidação de seus direitos. Ambas as reformas 
objetivavam a melhoria da atenção à saúde, mas cada uma a seu modo. Enquanto a Reforma Sanitária tomava os caminhos da institucionalização definitiva e universal da saúde, a Reforma Psiquiátrica voltava-se prioritariamente para as transformações das ações de saúde, para a desconstrução. Mas, apesar de tomarem rumos relativamente diferentes, as duas reformas se complementam, como se pode observar na atual política de saúde mental ${ }^{(6)}$.

Por todo o Estado do Paraná (Estado do qual faz parte a cidade e o local de estudo) distribuem-se unidades básicas de saúde (UBS), ambulatórios de saúde mental, CAPS, hospital dia, leitos em hospitais gerais, destinados a pacientes psiquiátricos e hospitais psiquiátricos. As UBSs constituem os serviços de menor complexidade em relação ao atendimento em saúde mental. Contudo, são essas as responsáveis pela promoção, prevenção e reconhecimento de patologias psiquiátricas, especialmente em cidades ou regiões com menos de 50 mil habitantes ${ }^{(8)}$.

Em Londrina, PR, os usuários com transtorno mental recebem assistência das UBSs e, de acordo com o caso, são encaminhados para o CAPS III ou CAPS AD (Centro de Atenção Psicossocial - Álcool e Drogas) ou CAPSi (Centro de Atenção Psicossocial - Infantil). Esses Centros de Atenção Psicossocial estão presentes em municípios com mais de 200 mil habitantes. Em municípios com população entre 20 a 70 mil habitantes, a demanda é atendida pelos CAPS I, de menor porte, e os CAPS II de médio porte, para cidades de 70 a 200 mil habitantes ${ }^{(8-9)}$.

Em relação à $\mathrm{ABS}$, essa corresponde ao primeiro nível de contato dos usuários com o cuidado formal oferecido por um sistema de saúde. Deve ser capaz de atender todos os transtornos incidentes sobre a população sob sua responsabilidade, exceto os incomuns e/ou

$$
\begin{array}{ccccccc}
\text { SMAD } 2010 & \begin{array}{c}
\text { Nolume } \\
\text { Volumen }
\end{array} & 6 & \text { Numero } & 2 & \text { Artigo } \\
& \text { Aumber } & \text { Article } & 6 & \text { SMAD, Revista Eletrônica Saúde Mental } \\
& & & \text { Álcool e Drogas }
\end{array}
$$


mais complexos, cuja competência é relativa aos níveis secundário e terciário de atenção à saúde. Todavia, os transtornos mentais são tão prevalentes quanto se mostrou numa pesquisa realizada em São Paulo, SP, na qual se constatou que pelo menos $46 \%$ da população pode apresentar algum transtorno mental durante a vida ${ }^{(10)}$.

A $\mathrm{OMS}^{(11)}$, entretanto, afirma que o reconhecimento dos transtornos mentais na atenção básica, por parte dos profissionais, é de baixa a moderada na melhor das hipóteses, isto é, frequentemente há falhas na detecção desses transtornos. Isso leva a se refletir acerca da importância da capacitação dos profissionais, pois, os mesmos lidam diariamente com inúmeros usuários com transtornos mentais. A cada ano, aproximadamente 1.500 trabalhadores participam de cursos com duração superior a 360 horas, e 6,000 trabalhadores de diferentes níveis de escolaridade participam de cursos de 40 horas, com enfoque em saúde mental na atenção básica ${ }^{(12)}$.

Médicos e enfermeiros geralmente adquirem conhecimentos básicos em saúde mental em sua formação acadêmica. Contudo, uma pesquisa ${ }^{(13)}$ demonstrou que os médicos da atenção básica nem sempre têm o preparo adequado para a abordagem dos transtornos mentais, seja devido à falta de alguns conhecimentos específicos ou devido a cursos de atualização de má qualidade, cuja metodologia de ensino não é capaz de atender as necessidades apresentadas nas UBSs. Embora o assunto principal deste estudo não seja a formação médica, coube aqui apenas fazer pequena ressalva em relação a ela, devido à repercussão no processo de trabalho do enfermeiro e do restante da equipe de saúde.

$\begin{array}{lllllll}\text { SMAD } 2010 & \text { Volume } & & \text { Número } & \text { Artigo } & \\ \text { Volumen } & 6 & \text { Numero } & 2 & \text { Artículo } & 6 & \text { SMAD, Revista Eletrônica Saúde Mental } \\ & & \text { Number } & \text { Article } & \text { Álcoole Drogas }\end{array}$ 
Os enfermeiros, por sua vez ${ }^{(14)}$, não sabem identificar pacientes com sintomatologia depressiva, assim como não observam esses indicadores nos pacientes por eles atendidos, e, ainda, muitos não entendem que seja sua tarefa fazer essa identificação.

Os ACSs, dentre os demais membros da equipe, se destacam pelo contato com casos de portadores de transtornos mentais, demonstrando conhecimento dessa problemática na sua realidade e referindo habilidade para identificar os mesmos sem que, necessariamente, tenham sido capazes de oferecer solução adequada para o mesmo. Entretanto, é oportuno destacar que essa habilidade para identificar os portadores de transtornos mentais é autorreferida e, em alguns casos, origina dúvidas em relação à real capacidade para identificação, pois nem todos os ACSs recebem a capacitação adequada, apesar de não haver equívoco quanto ao seu maior contato com os portadores de transtornos mentais ${ }^{(13)}$.

A capacitação do ACS é de responsabilidade principalmente do enfermeiro supervisor de seu trabalho, como consta na Portaria 1886/GM, de 18 de dezembro de 1997, que aprova as Normas e Diretrizes do Programa de Agentes Comunitários de Saúde e do Programa de Saúde da Família: "São consideradas atribuições básicas dos enfermeiros instrutores/supervisores planejar e coordenar a capacitação e educação permanente dos ACSs, executando-a com participação dos demais membros da equipe de profissionais do serviço local de saúde ${ }^{15}$ ". Por conseguinte, quando detectada a necessidade de melhor preparo para lidar com determinadas situações, é o enfermeiro supervisor quem deve se prontificar a oferecer o treinamento apropriado.

\footnotetext{
$\begin{array}{ccccccc}\text { SMAD } 2010 & \text { Volume } & & \text { Número } & \text { Artigo } & \\ \text { Volumen } & 6 & \text { Numero } & 2 & \text { Artículo } & 6 & \text { SMAD, Revista Eletrônica Saúde Mental } \\ & & \text { Number } & \text { Article } & & \text { Álcool e Drogas }\end{array}$
} 
Ao realizar análise do conteúdo mínimo do curso introdutório para a Estratégia de Saúde da Família ${ }^{16}$, ditada pela Portaria 2527, de 19/10/2006, percebe-se que o tema saúde mental não está claramente definido, uma vez que os eixos principais são as políticas de saúde, processo de trabalho e organização do sistema de saúde. O questionamento cabível é se a saúde mental está representada dentro desses eixos ou fica marginalizada como assunto a ser discutido e trabalhado.

\section{Metodologia}

Trata-se de estudo que utiliza a abordagem qualitativa, buscando conhecer a percepção do ACS, quanto ao seu preparo para identificar depressão. A pesquisa qualitativa é constituída por um conjunto de práticas interpretativas, como a busca de generalidades e diferenças nas respostas e condutas dos sujeitos, com o objetivo de contrastar e organizar elementos. Assim, este estudo envolveu a observação pelos sujeitos de suas próprias situações reais e cotidianas do trabalho ${ }^{(17)}$. Com o material obtido, foram elaboradas categorias de discussão, descritas na seção de análise e discussão dos resultados.

\section{Local e período da pesquisa}

O local de estudo foi uma UBS da zona sul do município de Londrina, PR, que assiste população de aproximadamente 10 mil habitantes. Atuam nesse serviço o total de oitenta e 
três funcionários dos quais vinte e quatro se distribuem entre as três equipes de ESF. Este estudo teve como meta servir de base para a elaboração da monografia da autora, não recebendo nenhum tipo de patrocínio.

As equipes realizam atividades de promoção, prevenção, tratamento e reabilitação em saúde, tais como ações educativas em escolas, tratamento e monitoramento de pacientes hipertensos e diabéticos, acompanhamento de gestantes e puérperas, visitas domiciliares a pacientes acamados, enfim, como a maioria as equipes de ESF existentes no país, essas assistem população bastante heterogênea quanto à faixa etária e quanto às necessidades de saúde.

Diante disso, as ESFs em questão muitas vezes se deparam com problemas de saúde mental. Quando são detectados esses problemas, é avaliada a gravidade e realizado o tratamento ou encaminhamento ao CAPS. Contudo, cabe observar que até a realização da presente pesquisa, as ESFs não desenvolviam ou desenvolveram atividades relacionadas à saúde mental que não o acompanhamento acima referido.

O período de pesquisa compreendeu os meses de março a novembro de 2009 , sendo os dois primeiros meses destinados ao levantamento de dados, os três seguintes à tramitação no Comitê de Ética em Pesquisa da Universidade Estadual de Londrina e, em meados de setembro, realizada a coleta de dados consecutiva à análise e discussão dos resultados.

\section{Coleta de dados e sujeitos}

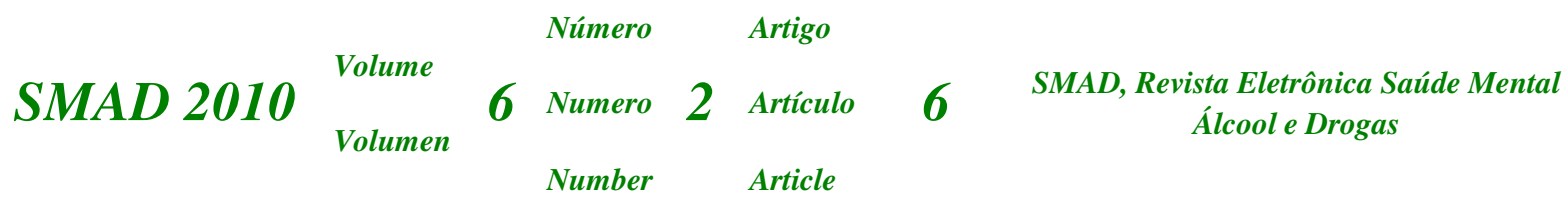


O passo inicial do processo de coleta de dados foi iniciado pela tramitação junto ao Comitê de Ética em Pesquisa do Hospital Universitário da Universidade Estadual de Londrina, o qual emitiu o Parecer de aprovação do projeto de pesquisa. Após essa aprovação, procedeu-se ao convite verbal de dois sujeitos para participar do pré-teste, sendo excluídos após essa fase.

Após essa etapa, foram convidados, verbalmente, para a pesquisa dez ACSs, pertencentes à ESF estudada. Tanto na etapa de pré-teste como na de coleta real, foi programado o horário que menos coincidisse com as tarefas de trabalho dos sujeitos, a fim de que pudessem ser explicados os objetivos da pesquisa, seus critérios de participação e o convite para participar do estudo, mediante as normas éticas de pesquisa com seres humanos e para, também, responder as questões com tranquilidade.

Os critérios de inclusão no estudo foram ser ACSs da ESF e aceitar as condições éticas da pesquisa com seres humanos. Os critérios de exclusão foram: ter ou cursar nível superior de Enfermagem, assim como outros cursos que possuam interface com a saúde mental, como psicologia, medicina, farmácia etc. e/ou não aceitar as normas éticas de pesquisa com seres humanos. Um sujeito foi excluído da pesquisa por não desejar participar do estudo, mas não por essas condições supracitadas.

\section{Instrumentos de coleta de dados}

Elaborou-se questionário com perguntas abertas e autoaplicáveis. Foram realizadas sete perguntas, uma referente ao tempo de trabalho na ESF, quatro referentes à formação e

$$
\begin{array}{ccccccc}
\text { SMAD } 2010 & \begin{array}{c}
\text { Nolume } \\
\text { Volumen }
\end{array} & 6 & \text { Numero } & 2 & \text { Artigo } \\
& \text { Aumber } & \text { Article } & 6 & \text { SMAD, Revista Eletrônica Saúde Mental } \\
& & & \text { Álcool e Drogas }
\end{array}
$$


conhecimentos do ACS em relação a transtornos mentais, uma referente à supervisão do enfermeiro e educação continuada e a última ao atendimento de indivíduos com transtorno mental. A etapa de pré-teste possibilitou que fosse possível identificar falhas na redação da linguagem de três questões, mostradas a seguir.

1. Fale sobre seus conhecimentos em saúde mental. 2. Como você caracteriza a supervisão da enfermeira com relação aos conhecimentos de saúde mental? 3. Como funciona o atendimento das pessoas com transtorno mental?

Essas foram substituídas pelas questões abaixo.

1.Você conhece pessoas com transtornos mentais? Como elas são ou como elas se comportam? 2. As enfermeiras da estratégia de saúde da família já realizaram algum treinamento sobre doenças mentais? Você acha que existe a necessidade do treinamento sobre esse assunto? 3. Quando é encontrada uma pessoa com transtorno mental, sua equipe passa a responsabilidade do caso para o CAPS ou acompanha o caso juntamente com o CAPS?

Os questionários foram entregues aos ACSs juntamente com o termo de consentimento livre e esclarecido, realizando-se também orientações para que o questionário fosse respondido individualmente, de acordo com os conhecimentos e experiências pessoais, sem o auxílio de livros, internet ou outras fontes de saber.

\section{Análise dos Dados}

A análise e interpretação dos dados consistiram em separar os elementos básicos da informação e examiná-los, de modo a responder às questões colocadas na pesquisa. A

$$
\begin{array}{cccccccc}
\text { SMAD } 2010 & \begin{array}{c}
\text { Nolume } \\
\text { Volumen }
\end{array} & 6 & \text { Numero } & 2 & \text { Artigo } \\
& & \text { Articulo } & 6 & \text { SMAD, Revista Eletrônica Saúde Mental } \\
& & & \text { Article }
\end{array}
$$


interpretação do material analisado foi o meio pelo qual se procurou inferir significado mais amplo para a percepção do ACS sobre seu cotidiano e conhecimento relatado.

Foi usado o método de análise descritiva (composto pela análise individual das perguntas, feita de acordo com as frequências alcançadas pelas diferentes respostas de cada sujeito a cada pergunta) e da análise descritiva geral (onde as respostas são agrupadas de acordo com as variáveis da pesquisa, partindo das mais gerais), de modo a identificar possíveis ligações entre a informação colhida e a problemática pesquisada, sendo possível comparar e avaliar a informação obtida, inferindo consistência às conclusões obtidas ${ }^{(18)}$.

\section{Resultados}

Foram entrevistados nove ACSs, sendo que oito do sexo feminino, com tempo de trabalho na equipe de ESF de, no mínimo, nove meses e, no máximo, oito anos. Não foi excluído nenhum individuo, uma vez que nenhum possuía formação educacional em nível superior, mas, no entanto, um sujeito não aceitou participar do estudo por motivos pessoais. Os dados obtidos originaram também a confecção da Tabela 1.

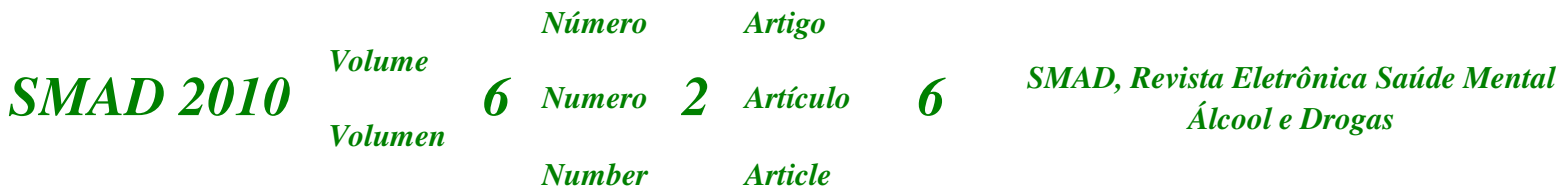


Tabela 1 - Respostas dos ACSs, segundo formação, conhecimento e assistência em saúde mental, Londrina, PR, 2009

\begin{tabular}{|c|c|c|c|c|c|c|c|}
\hline 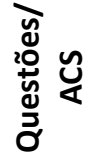 & $\begin{array}{l}\text { Tempo de } \\
\text { trabalho na } \\
\text { ESF }\end{array}$ & $\begin{array}{l}\text { Formação } \\
\text { como ACS }\end{array}$ & $\begin{array}{l}\text { Conhecimento } \\
\text { em saúde mental }\end{array}$ & $\begin{array}{l}\text { Conhecimento } \\
\text { sobre depressão }\end{array}$ & $\begin{array}{l}\text { Recebeu } \\
\text { Treina- } \\
\text { mento }\end{array}$ & $\begin{array}{l}\text { Necessidade } \\
\quad \text { do } \\
\text { treinamento }\end{array}$ & $\begin{array}{l}\text { Assistência } \\
\text { em saúde } \\
\text { mental }\end{array}$ \\
\hline 1 & 9 meses & Não teve & $\begin{array}{l}\text { Algumas são aparentemente normais, mas não } \\
\text { conseguem desenvolver as mesmas atividades } \\
\text { que pessoas normais. E outras se comportam de } \\
\text { forma irresponsável, como crianças }\end{array}$ & $\begin{array}{l}\text { Têm perda da autoestima, } \\
\text { tristeza, isolamento social, } \\
\text { não têm desejo de fazer } \\
\text { nada }\end{array}$ & Não & Não & $\begin{array}{l}\text { O caso é } \\
\text { acompanhado } \\
\text { pelo CAPS e a } \\
\text { equipe }\end{array}$ \\
\hline 2 & 10 meses & Não teve & $\begin{array}{l}\text { Pessoas um pouco agressivas e precisam de um } \\
\text { melhor tratamento, tanto da saúde como dos } \\
\text { cuidadores }\end{array}$ & $\begin{array}{l}\text { É uma doença que atinge o } \\
\text { lado emocional das pessoas }\end{array}$ & Não & Sim & $\begin{array}{l}\text { Existe } \\
\text { acompanham } \\
\text { ento pelo } \\
\text { CAPS e ESF }\end{array}$ \\
\hline 3 & 15 meses & Não teve & $\begin{array}{l}\text { Algumas são agressivas, outras falam sozinhas, } \\
\text { andam perambulando. Outras são quietas até } \\
\text { não demonstram muito devido ao uso da } \\
\text { medicação }\end{array}$ & $\begin{array}{l}\text { Isoladas, não desejam ter } \\
\text { contato com outras pessoas, } \\
\text { algumas deixam de se } \\
\text { alimentar, choram } \\
\text { constantemente e até } \\
\text { sentem desejo de morte e } \\
\text { suicídio }\end{array}$ & Não & $\begin{array}{l}\text { Sim, pois existem } \\
\text { casos na área, e o } \\
\text { treinamento pode } \\
\text { contribuir para } \\
\text { melhor lidar com } \\
\text { as situações }\end{array}$ & $\begin{array}{l}\text { É realizado } \\
\text { acompanham } \\
\text { ento com o } \\
\text { CAPS }\end{array}$ \\
\hline 4 & 15 meses & Não teve & $\begin{array}{l}\text { Pessoas com alteração/variação no } \\
\text { comportamento }\end{array}$ & $\begin{array}{l}\text { Tristes e incapazes de } \\
\text { realizar atividades } \\
\text { rotineiras, isolamento social }\end{array}$ & Não & $\begin{array}{l}\text { Sim, seria bem } \\
\text { interessante o } \\
\text { aprofundamento } \\
\text { no assunto }\end{array}$ & $\begin{array}{l}\text { O caso é } \\
\text { encaminhado } \\
\text { para o CAPS e } \\
\text { também é } \\
\text { acompanhado } \\
\text { pela ESF } \\
\text { Passa para o }\end{array}$ \\
\hline 5 & 15 meses & Não teve & $\begin{array}{l}\text { Agitadas, agressivas, sem discernimento, sem } \\
\text { capacidade de locomoção }\end{array}$ & $\begin{array}{l}\text { Isolamento social, labilidade } \\
\text { emocional, ideação suicida, } \\
\text { baixa autoestima }\end{array}$ & Não & Sim & $\begin{array}{l}\text { CAPS e } \\
\text { também } \\
\text { acompanha a } \\
\text { família }\end{array}$ \\
\hline 6 & 3 anos & Sim & $\begin{array}{l}\text { Varia. Algumas são agressivas, outras falam } \\
\text { coisas sem sentido }\end{array}$ & São transtornos do dia a dia & Não & Não & $\begin{array}{l}\text { Passa para o } \\
\text { CAPS }\end{array}$ \\
\hline 7 & 5 anos & $\begin{array}{l}\text { Após } 2 \\
\text { anos }\end{array}$ & Varia de pessoa para pessoa & $\begin{array}{l}\text { Ouvi falar sobre depressão, } \\
\text { mas não possuo } \\
\text { conhecimento para } \\
\text { descrever }\end{array}$ & Não & $\begin{array}{l}\text { Sim } \\
\text { É necessário mais } \\
\text { conhecimento para } \\
\text { melhor atender o } \\
\text { usuário }\end{array}$ & $\begin{array}{l}\text { Acompanha o } \\
\text { caso } \\
\text { juntamente } \\
\text { com o CAPS }\end{array}$ \\
\hline 8 & 7 anos & Sim & $\begin{array}{l}\text { São seres humanos e se comunicam como todo } \\
\text { mundo. Através da medicação são ótimas } \\
\text { pessoas }\end{array}$ & $\begin{array}{l}\text { Não nervosas, com } \\
\text { distúrbios, agitadas }\end{array}$ & Não & $\begin{array}{l}\text { Sim, pois tudo o } \\
\text { que se aprende se } \\
\text { acrescenta na } \\
\text { equipe }\end{array}$ & $\begin{array}{l}\text { Acompanha o } \\
\text { caso } \\
\text { juntamente } \\
\text { com o CAPS }\end{array}$ \\
\hline 9 & 8 anos & $\begin{array}{l}\text { Após } 6 \\
\text { anos }\end{array}$ & Podem ser tranquilas, agitadas ou agressivas & $\begin{array}{l}\text { Doença do século. As } \\
\text { pessoas podem morrer por } \\
\text { causa da doença }\end{array}$ & Não & Sim & $\begin{array}{l}\text { Acompanha o } \\
\text { caso } \\
\text { juntamente } \\
\text { com o CAPS }\end{array}$ \\
\hline
\end{tabular}




\section{Análise dos Dados e Discussão}

A análise dos dados permitiu a criação de categorias apresentadas a seguir, intituladas atitudes e conhecimento sobre transtornos mentais e depressão, capacitação em saúde mental e assistência em saúde mental e apoio matricial.

\section{Atitudes e conhecimento sobre transtornos mentais e depressão}

Todos os ACSs entrevistados referiram conhecer ou já ter tido contato com pessoas com algum transtorno mental. Eles reconhecem essas pessoas através do comportamento muitas vezes agressivo ou agitado se comparado com "pessoas normais". Corroborando outros estudos $^{(19)}$, também entre os ACSs está presente a ideia de que a pessoa com transtorno mental é facilmente identificável em função de características comportamentais destoantes do consenso construído pelo coletivo.

A agressividade surge em cinco dos nove sujeitos entrevistados, o que remete ao estereótipo da loucura presente na sociedade e que não é diferente em um ACS, pois, de acordo com a Tabela 1, houve um sujeito que, mesmo após realizar o curso de formação profissional, mantém o estereótipo do louco como pessoa violenta. Ao passo que outros dois sujeitos não tiveram formação de ACS abordam a agressividade como característica pessoal, assim como, também, outros dois sujeitos não realizaram o curso de formação, mas não retratam a agressividade como característica pessoal dos portadores de transtornos mentais.

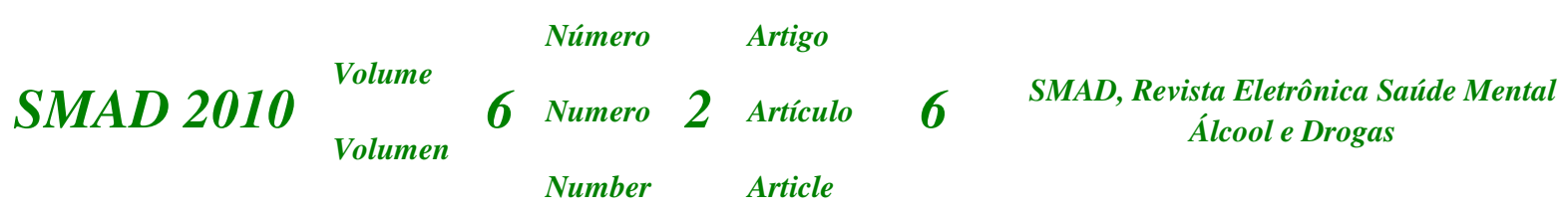


Diante desses dados, não é possível afirmar categoricamente que o curso de formação profissional para ACS possa ter sido fator diferencial ou não para a mudança de visão dos sujeitos, acerca dos portadores de transtornos mentais, dado que essa informação não fora obtida diretamente pelo questionário. No entanto, as demais respostas às outras questões direcionam o raciocínio no sentido de que o curso não tenha abordado tais questões e que a saúde mental tenha ficado à margem da formação profissional do ACS.

Apesar desse preconceito não ser completamente equivocado, pois existem situações que geram agressividade, nota-se viés de preconceito e "rotulação" do indivíduo. Assim, constata-se que existe a necessidade de maior conhecimento sobre o tema, pois, muitas vezes, a falta de compreensão pode gerar, além do preconceito, medo em relação aos usuários portadores de transtornos mentais, causando prejuízos na relação usuário x ESF. Autores ${ }^{(20)}$ reconhecem que os ACSs realizam importante tarefa no acompanhamento de doentes mentais.

Os agentes comunitários de saúde têm um contato bastante próximo e importante com doentes mentais. Em muitas situações é o agente comunitário quem realiza o primeiro atendimento e providencia o encaminhamento necessário. Além disso, acompanha os pacientes nas consultas junto ao serviço de saúde mental, no domicílio averiguando se a medicação vem sendo utilizada e assessorando a família no cuidado desse doente.

Assim, o autor demonstra a importância desse ator social conhecer a problemática e ainda reflete acerca da sua formação em saúde mental, ou a ausência dela, sobre a qualidade da assistência prestada. Sobre a depressão, chama a atenção o fato de que os sujeitos que não sabiam descrever seus conhecimentos sobre depressão, ou que apresentavam conhecimentos errôneos, foram aqueles que referiram ter realizado o curso de formação profissional, ao passo

$$
\begin{array}{ccccccc}
\text { SMAD } 2010 & \text { Volume } & & \text { Número } & \text { Artigo } & \\
\text { Volumen } & 6 & \text { Numero } & 2 & \text { Artículo } & 6 & \text { SMAD, Revista Eletrônica Saúde Mental } \\
& & \text { Number } & \text { Article } & & \text { Álcool e Drogas }
\end{array}
$$


que os demais descreveram vários sintomas característicos do transtorno, ou seja, o curso de formação profissional dos ACSs não propiciou aquisição de conhecimentos adequados.

Logo, se entende que seus conhecimentos são relacionados às experiências de vida ou ao senso comum, já que nenhum deles referiu ter realizado algum tipo de capacitação sobre o assunto, assim como parece tornar mais clara a possibilidade de que o curso de formação não tenha sido fator diferencial para a mudança de atitude em relação aos portadores de transtornos mentais.

A depressão é transtorno relativamente prevalente e conhecido pelos ACSs, embora, seja imperativo o treinamento para melhor compreensão da doença, especialmente quanto às implicações físicas, sociais e psicológicas.

\section{Capacitação em saúde mental}

Apesar da grande variação de tempo de trabalho na ESF, nenhum dos ACSs referiu ter realizado algum outro curso ou treinamento que não fosse o de formação de agentes comunitários de saúde, tampouco receberam alguma orientação sobre doenças mentais por parte das enfermeiras da ESF. Portanto, quando questionados acerca da necessidade de treinamento sobre doenças mentais, sete dos nove indivíduos afirmaram existir a necessidade de treinamento, justificada pela existência de casos de transtornos mentais em sua área de atuação e necessidade do preparo para lidar com tais situações.

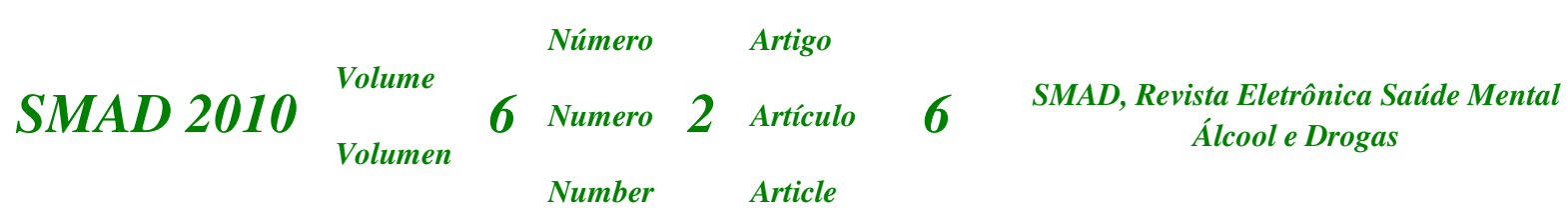


O trabalho do ACS é bastante complexo se considerado seu conhecimento diante de seus deveres. Em um estudo sobre os $\mathrm{ACSs}^{(21)}$, concluiu-se que os mesmos não dispõem de instrumentos e de tecnologia, aqui incluídos os saberes para o seu trabalho. Essa insuficiência faz com que trabalhem com o senso comum, com a religião e, mais raramente, com os saberes e os recursos das famílias e da comunidade.

Faz-se necessário, consequentemente, seu treinamento sobre temas ligados à saúde mental, sobre os transtornos mentais e depressão, não somente pelo novo paradigma criado pela Reforma Psiquiátrica, que centraliza a assistência na atenção básica, mas também pela própria demanda do serviço, conforme referido pelos ACSs (Tabela 1).

Deve-se considerar outro aspecto relativo ao papel do ACS: seu trabalho baseia-se em identificar fatores de risco e sinais de alerta de determinadas doenças assim como encaminhar, orientar e acompanhar esses usuários. Se ele deve identificar, devem ser oferecidos subsídios para tal. De acordo com a já citada Portaria 1886/GM, de 18 de dezembro de 1997, que aprova as Normas e Diretrizes do Programa de Agentes Comunitários de Saúde e do Programa de Saúde da Família, o enfermeiro supervisor do ACS é o principal responsável pela sua capacitação. Porém, nem sempre essa capacitação é realizada, o que causa prejuízo para os usuários que deixam de ser adequadamente assistidos ${ }^{(15)}$.

Observa-se, portanto, que, apesar de não terem recebido capacitação em saúde mental, os ACSs percebem a necessidade de tal demanda. Também, o novo paradigma da Reforma Psiquiátrica exige, de certa forma, melhor preparo por parte da atenção básica, pois pouco

$$
\begin{array}{ccccccc}
\text { SMA } 2010 & \text { Volume } & \text { Número } & \text { Artigo } & \\
\text { Volumen } & 6 & \text { Numero } & 2 & \text { Artículo } & 6 & \text { SMAD, Revista Eletrônica Saúde Mental } \\
& & \text { Number } & \text { Article } & \text { Álcoole Drogas }
\end{array}
$$


resolve centralizar a assistência em saúde mental na atenção básica se ela própria não encontra condições para lidar com a problemática.

\section{Assistência em saúde mental e o apoio matricial}

Do acompanhamento dos casos de transtornos mentais, oito participantes da pesquisa relataram haver acompanhamento mútuo por parte do CAPS e ESF, ou seja, existência do apoio matricial nos casos em que a ESF necessita de subsídios para seu trabalho.

Os ACSs entendem que alguns usuários com transtornos mentais necessitam de suporte mais especializado que aquele oferecido pela ESF e reconhecem que os usuários não devem somente ser encaminhados para o CAPS, e, sim, a ESF, juntamente com a equipe do CAPS, deve assistir o usuário. Isso representa o acompanhamento mútuo dos casos ou a corresponsabilização pelo tratamento do usuário, ou seja, o apoio matricial.

As equipes de saúde mental devem oferecer apoio matricial às ESFs para que essas consigam o máximo de sucesso em suas intervenções, contribuindo para que não exista a necessidade de encaminhar as pessoas para níveis mais complexos de atenção ${ }^{(22)}$. Dessa maneira, diminui-se tanto os custos monetários de uma internação ou especialidade médica quanto a estigmatização e o preconceito voltados às pessoas com transtornos mentais.

O apoio matricial, portanto, constitui ferramenta determinante para o atendimento do usuário com transtornos mentais, afinal, a atenção básica nem sempre apresenta tecnologia

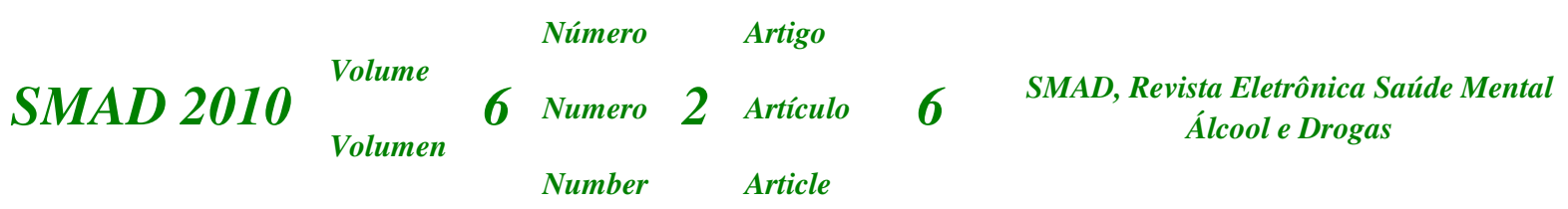


suficiente para resolução de determinadas situações, mas possui o vínculo e a proximidade com o usuário que torna as intervenções mais efetivas do ponto de vista terapêutico.

\section{Considerações Finais}

Conclui-se com a pesquisa que a percepção dos agentes comunitários da equipe estudada, quanto ao seu preparo para identificar depressão, é negativa, ou seja, referem não ter recebido preparo e apenas dois sujeitos o consideram importante. Como em muitos casos, os ACSs não possuem treinamento ou capacitação em saúde mental, porém, possuem conhecimentos baseados no senso comum ou em experiências pessoais que, de alguma forma, os influenciam no acompanhamento de usuários com transtornos mentais e/ou depressão, confirmando-se, também, que os transtornos mentais são relativamente prevalentes na sua prática diária.

Compreendeu-se que o preparo do ACS ainda é precário, se considerado como importante o papel que ele exerce: identificar problemas e encaminhar o usuário para o serviço de saúde. As respostas dadas pelos sujeitos dão indícios de que a saúde mental está marginalizada, ou excluída do planejamento da capacitação e dos cursos de formação profissional do ACS.

Permanece o questionamento, ainda, de que sendo o enfermeiro considerado o instrutor e responsável pelas ações e pelo treinamento do ACS, estaria ele preparado para

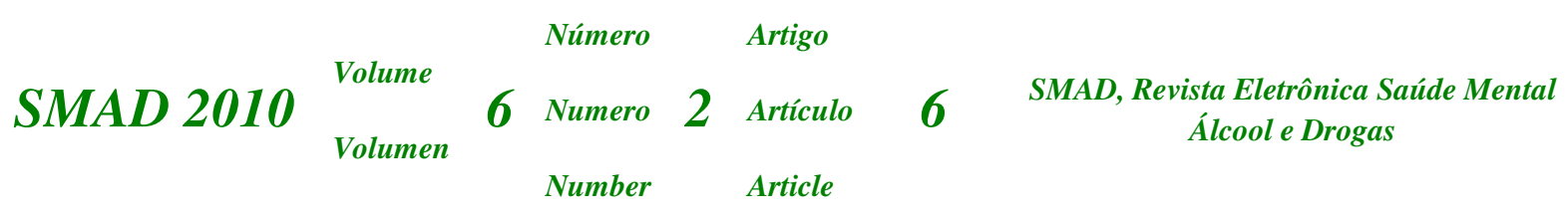


capacitar ações básicas de saúde mental? Essa foi questão apresentada justamente para refletir sobre o importante papel do enfermeiro, já que nenhum dos sujeitos referiu ter recebido alguma orientação ou capacitação dada pelo enfermeiro, supervisor e responsável pelo seu trabalho.

Embora o objetivo deste estudo não tenha sido investigar essa questão, apresentada no parágrafo anterior, acredita-se que a pesquisa pôde trazer contribuições no sentido de repensar a prática e a formação do ACS, para a melhoria da assistência em saúde mental, e contribuir para a consolidação da Reforma Psiquiátrica. Sugere-se a continuidade das pesquisas sobre esta temática, assim como, também, reitera-se que este estudo não visou esgotar o tema.

\section{Referências}

1. Ministério da Saúde (BR). Guia prático do programa saúde da família. Brasília (DF): Ministério da Saúde; 2001.

2. World Health Organization. Depression. [acesso em: 01 nov 2009]. Disponível em: http://www.who.int/mental_health/management/depression/definition/en/

3. Stroppa ALPC. Transtornos do humor em atenção básica a saúde. In: Ribeiro MS, organizador. Ferramentas para descomplicar a atenção básica em saúde mental. Juiz de Fora (MG): Universidade Federal de Juiz de Fora; 2007.

4. Organização Mundial da Saúde. Relatório mundial da saúde 2001. Saúde mental: nova

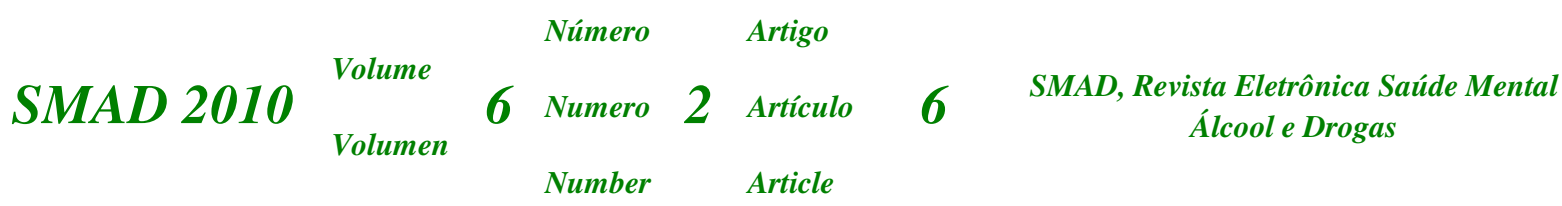


concepção, nova esperança. Genebra: Organização Mundial da Saúde; 2001.

5. Fortes S, Villano LAB, Lopes CS. Nosological profile and prevalence of common mental disorders of patients seen at the Family Health Program units in Petrópolis, Rio de Janeiro. Rev Bras Psiquiatr. 2008;30(1):32-7.

6. Ogata MN, Furegato ARF, Saeki T. Reforma sanitária e reforma psiquiátrica no Brasil: convergências e divergências. Nursing. 2000;3(25):24-9.

7. Ministério da Saúde (BR). III Conferencia Nacional de Saúde Mental: Caderno Informativo. Brasília (DF): Ministério da Saúde; 2001.

8. Secretaria de Estado da Saúde do Paraná (BR). Programa Saúde Mental na Comunidade. [acesso em: 04 out 2009]. Disponível em: http://www.saude.pr.gov.br/modules/conteudo/conteudo.php?conteudo=582

9. Ministério da Saúde (BR). Reforma psiquiátrica e política de saúde mental no Brasil. Brasília (DF): Ministério da Saúde; 2005.

10. Ribeiro MS, Poço JLC, Pinto AR. A inserção da saúde mental na atenção básica. In: Ribeiro MS, organizador. Ferramentas para descomplicar a atenção básica em saúde mental. Juiz de Fora (MG): Universidade Federal de Juiz de Fora; 2007.

11. World Health Organization (WHO). Integrating mental health into primary care: a global perspective. Geneva: WHO/WONCA; 2008.

12. Ministério da Saúde (BR). Saúde Mental no SUS: Acesso ao Tratamento e Mudança do Modelo de Atenção. Brasília (DF): Ministério da Saúde; 2007.

13. Nunes M, Jucá VJ, Valentim CPB. Ações de saúde mental no Programa Saúde da Família:

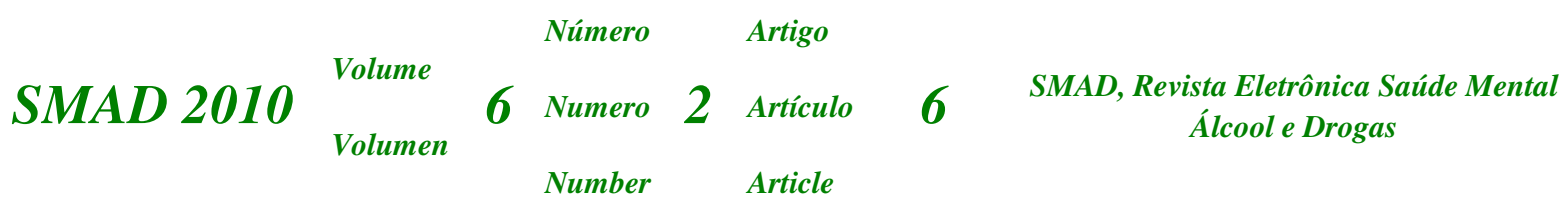


confluências e dissonâncias das práticas com os princípios das reformas psiquiátrica e sanitária. Cad Saúde Pública. 2007;23(10):2375-84.

14. Silva MCF, Furegato ARF, Costa ML Júnior. Depressão: pontos de vista e conhecimento de enfermeiros da rede básica de saúde. Rev. Latino-Am. Enfermagem. 2003;11(1):7-13.

15. Portaria n. 1886/GM (BR), de 18 de dezembro de 1997 Aprova as Normas e Diretrizes do Programa de Agentes Comunitários de Saúde e do Programa de Saúde da Família. [acesso em: 01 nov 2009]. Disponível em http://www.saude.gov.br

16. Portaria n. 2527 (BR), de 19 de outubro de 2006. Define os conteúdos mínimos do Curso Introdutório para profissionais da Saúde da Família. [acesso em: 01 nov 2009]. Disponível em http://www.saude.gov.br

17. Deslandes SF, Assis SG. Abordagens quantitativa e qualitativa em saúde: o diálogo das diferenças. In: Minayo MCS, Deslandes SF, organizadoras. Caminhos do pensamento: epistemologia e método. Rio de Janeiro (RJ): Fiocruz; 2002.

18. Soriano RR. Manual de pesquisa social. Petrópolis (RJ): Vozes; 2004.

19. Barros MMMA. Chagas MIO, Dias MSA. Saberes e práticas do agente comunitário de saúde no universo do transtorno mental. Ciênc Saúde Colet. 2009;14(1):227-32.

20. Miron VL, Hildebrandt LM, Vargas D, Menezes A, Charneski G, Franco GF, Scherer LM. Formação do pessoal de enfermagem no campo da saúde mental. In: Labate RC, organizadora. Caminhando para a assistência integral. Ribeirão Preto (SP): Scala; 1999.

21. Silva JA. O agente comunitário de saúde do Projeto Qualis: agente institucional ou agente de comunidade? Tese [doutorado]. São Paulo: Faculdade de Saúde Pública/USP; 2001.

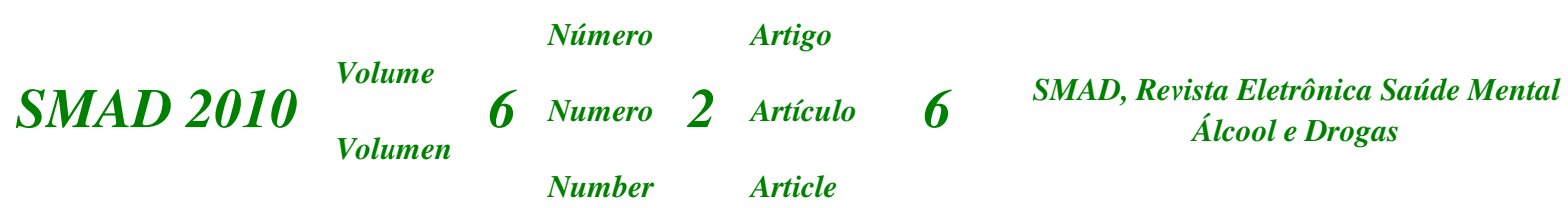


22. Amarante P. Saúde mental e atenção psicossocial. 2.ed. Rio de Janeiro (RJ): Fiocruz; 2008.

Recebido em: 24/02/2010

Aprovado em: 05/04/2010

\section{Como citar este artigo:}

Harada OL, Soares MH. A percepção do agente comunitário de saúde para identificar a depressão. SMAD, Rev. Eletrônica Saúde Mental Álcool Drog. (Ed. port.) [Internet]. 2010 [acesso em: dia mês abreviado com ponto ano] ; 6(2):315-36. Disponível em: Endereço Eletrônico Visitado.

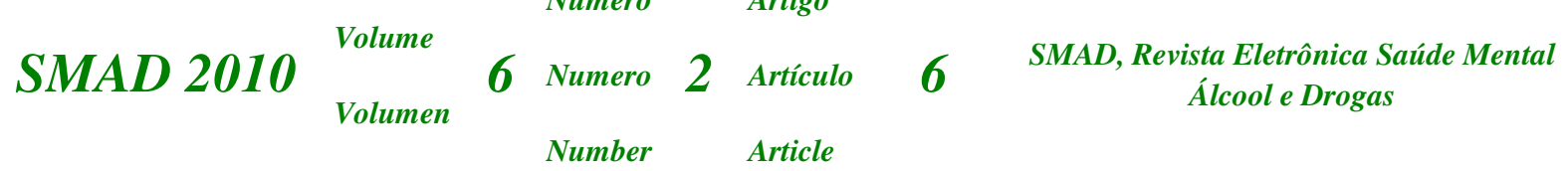

